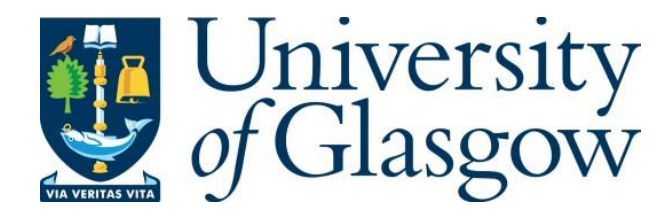

Yan, D., Kong, Y., Ren, X., Shi, Y. and Chiang, S. (2019) The determinants of urban sustainability in Chinese resource-based cities: A panel quantile regression approach. Science of the Total Environment, 686, pp. 1210-

1219. (doi:10.1016/j.scitotenv.2019.05.386)

There may be differences between this version and the published version. You are advised to consult the publisher's version if you wish to cite from it.

http://eprints.gla.ac.uk/194185/

Deposited on: 12 September 2019

Enlighten - Research publications by members of the University of Glasgow http://eprints.gla.ac.uk 


\title{
The Determinants of Urban Sustainability in Chinese Resource- based cities: A Panel Quantile Regression approach
}

\author{
Dan Yan ${ }^{1,3}$, Ying Kong ${ }^{1}$, Xiaohang Ren ${ }^{2, *}$, Yukun $\mathrm{Shi}^{4}$, SumWai Chiang ${ }^{1}$ \\ 1. Tsinghua-Berkeley Shenzhen Institute, Tsinghua University, Shenzhen 518055, \\ China
}

2. School of Mathematical Sciences, University of Southampton, Southampton SO17 1BJ, UK

3. Research Center for Transition and Development of Resource-exhausted Cities, Hubei Normal University, Huangshi, 435002, China

4. Adam Smith Business School, University of Glasgow, Glasgow G12 8QQ, UK

* Correspondence: x.ren@ soton.ac.uk; Tel.: +44 7761618538

\begin{abstract}
:
Improving energy efficiency and reducing environmental pollution emissions are two important ways to alleviate energy problems. Despite the progress in energy efficiency, the growth in energy demand still exceeds the efficiency improvements. This study adopts nonparametric methods to estimate the total factor energy efficiency (TFEE) of 105 resource-based cities covering the period 2010-2016 in China and analyzes the spatiotemporal characteristics of changes in energy efficiency. Furthermore, panel quantile regression is applied to analyze the multiple impacts of economic level, industrial structure, resource endowment, energy price, government intervention and degree of openness on energy efficiency. The main findings are as follows. (1) Each determinant has a different influence on TFEE at different levels; among them, the influence of the fuel and energy price index show an inverted U-shaped distribution as the quantile increases, and that of the GDP per capita shows a stronger heterogeneity than those of other factors. (2) Resource-based cities with lower efficiency are more sensitive to government intervention than are cities with higher efficiency. (3) A city's openness has a negative effect on TFEE, which partly supports the pollution haven hypothesis: the more foreign investment a resource-based city receives, the lower its
\end{abstract}


energy and technology efficiency. Finally, some practical suggestions for the sustainable development of resource-based cities are discussed.

Keywords: Urban Sustainability; Resource-based city; Quantile panel regression; nonparametric analysis

\section{Introduction}

The Fifth Assessment Report of the Intergovernmental Panel on Climate Change (IPCC) shows that the total GDP of the urban economy accounts for $80 \%$ of global GDP, its total energy consumption accounts for 67\%-76\% of global energy consumption, and its total carbon dioxide emissions account for $71 \%-76 \%$ of global emissions (IPCC, 2015). It is thus evident that cities contribute to energy consumption and the associated environmental impacts, furthermore, cities are most responsible for green development transformation and emission reduction actions ( $\mathrm{Li}$ et al., 2018). Over the past 40 years, China has experienced the most rapid development of urbanization in human history. Its urbanization rate increased from $17.92 \%$ in 1978 to $58.52 \%$ in 2017, while the population increased from 0.96 billion to 1.39 billion. During the development of the urban regional economy, numerous problems arose, such as great resource consumption, environmental contamination and ecosystem destruction, which restrict sustainable urban development. Given that resource shortages are increasingly hindering economic and social development, the global community is actively seeking sustainable development strategies. Energy efficiency exactly provides a solution to this contradiction, as efficiency enhancement means consuming less energy while producing more output (CEEEE, 2018). Although it has been greatly improved in many countries, regions and sectors, the increase in energy demand still exceeds its improvement (IEA, 2018). As a rapidly developing emerging economy, China's energy needs for social production and people's livelihood are great compared with those of other countries, and efficiency improvement is the necessary approach to achieve sustainable development. Against this background, strengthening the research on energy efficiency at various scales is crucial to enable us to understand how to promote its full effect from different dimensions.

Resource-based cities usually rise or grow due to the exploitation of natural resources, and resource-dependent industries occupy a larger share of their industrial structure ( $\mathrm{Li}$ et al., 2013). This concept is widely used, but different methods are 
adopted by governments and scholars to identify resource-based cities. Therefore, there is no unified understanding of what kind of cities can be identified as resource based. The definition for resource-based cities has gone through a process from simple to complex, from qualitative to quantitative, and from covering a single index to covering multiple indexes (Aurousseau M, 1921; Harris, 1943; Nelson and Howard, 1955). Many resource-based cities have gradually formed in China during the process of resource exploitation, and most developed during the central planning period. Specifically, two modes of city formation follow the order of resource extraction and urban development. One is "mining before the city"; that is, the city is formed completely due to resource exploitation, as was the case for Daqing, Jinchang, Panzhihua and Karamay. The other is "the city before mining"; that is, resource extraction accelerated urban development, but the city existed before resource extraction began, as was the case for Datong and Handan. Cities at different stages of resource development have different levels of economic and social development and face different problems. Therefore, it is necessary to classify the types of resourcebased cities to acquire a good knowledge of their current situation and formulate an overall plan. In 2013, the National Sustainable Development Plan for Resource-based Cities promulgated by the State Council screened 262 cities from 334 prefecture-level administrative units in China to be identified as resource-based cities, among them 128 prefecture-level cities, 62 county-level cities, 58 counties and 14 municipal districts covering a total area of 3.8 million $\mathrm{km}^{2}$ and accounting for $40 \%$ of the national area. The total population is 440 million, accounting for $33 \%$ of the national population ( $\mathrm{Yu}$ et al., 2018). Furthermore, according to their capacity for resource support and sustainable development, a total of 262 resource- based cities are divided into four types, namely growth-type, maturity-type, recession-type and regeneration-type.

Cities can be classified as resource-based cities and nonresource-based cities. The economic development of resource-based cities mainly depends on the exploitation and initial processing of resources. Compared with other cities, resource-based cities show obvious characteristics of high dependence on resources, periodicity of the urban development process, looseness of urban spatial structure and simplicity of industrial structure. Sustainable development requires economic construction while ensuring the environmental protection and sustainable utilization of the resources specific to resource-based cities, including the sustainable development of resource-based industries and the urban economy and society. However, rapid industrialization and 
urbanization have greatly promoted the energy demand in resource-based cities. Extensive energy use methods inevitably result in energy waste and ecological environment destruction. In brief, the main contradictions faced by resource-based cities in pursuit of sustainable development are overreliance on resource-based industries in the economic structure, social and livelihood problems caused by industrial restructuring, and environmental degradation caused by urban growth. In light of this, resource-based cities were regarded as research object, this study aims to investigate the causal relationship between TFEE and six economic and social variables of resource-based cities.

Taking China as a sample, this study explores the sustainable urban morphology of developing countries, which is quite meaningful for promoting urban transformation and enhancing urban competitiveness. To be clear, energy efficiency refers to a general term, and a variety of indicators can be used to measure it. Partial Factor Energy Efficiency (PFEE) is measured by the ratio of energy input to output, without considering other factors. Total Factor Energy Efficiency (TFEE) is measured by a complex input-output relationship, considering the substitution effect of multiple factors. Abbreviations for professional nouns in this study are shown in Table 1.

Table 1 Full names of abbreviations

\begin{tabular}{ll}
\hline Abbreviation & Full name \\
\hline PFEE & Partial Factor Energy Efficiency \\
TFEE & Total factor energy efficiency \\
DEA & Data envelopment analysis \\
DMU & Decision making unit \\
SFA & Stochastic frontier analysis \\
GPC & GDP per capita \\
IND & Proportion of secondary industry to GDP \\
MP & Proportion of mining industry population to the working \\
& population \\
FE & Proportion of fiscal expenditure to GDP \\
PRI & Fuel and energy price index \\
FC & Amount of foreign capital utilized in fixed assets investment \\
\hline
\end{tabular}

\section{Literature review}

\subsection{The approaches used in TFEE measurement}

The term energy conservation was proposed in the 1970s to address the constraints of energy on economic development, but scarce nonrenewable energy will continue to occupy a large proportion of future energy consumption, and mere energy conservation 
cannot solve the key issues. Instead, energy efficiency signifies the attainment of as much useful output as possible with the least possible energy factor inputs. Originally, scholars were concerned with only the relationship between energy efficiency and economic growth and did not bring environmental elements into the research scope. However, with global environmental deterioration becoming one of the greatest problems that must be addressed, environmental pollution was incorporated into the exogenous economic growth model. The efficiency indicators established previously fall into two categories. First, scholars have built a framework with a single energy input, which is often expressed in terms of unified, macroscopically aggregated indicators and standardized energy input (Rafiq et al., 2016). The existing literature mainly studies the relationship between energy intensity and industrial structure, economic level, urbanization and degree of opening up (Elliott et al., 2017). Ma Ben (2015) empirically examined the relative magnitude of the indirect effects of urbanization on energy intensity in each channel. However, the regional distribution of the economy is determined by not only energy use but also capital and labor input. The traditional measurement based on the simple ratio of input to output is not sufficiently comprehensive (Feng and Wang, 2017). Moreover, owing the interaction between various input factors, the increment in energy efficiency depends on total factor productivity (TFP). The second category of indicators concerns the total factor energy efficiency (TFEE) under a framework with multiple inputs and outputs, which includes labor, capital and other factors on the basis of the former single energy input framework. This framework also includes environmental pollution to fully reflect the relationships between energy efficiency and various factors from the perspective of the energyenvironment-economy triad (Hu and Wang, 2006). Using this framework, scholars have analyzed the TFEE at different scales and from various dimensions. The two tools most frequently used for TFEE measurement are parametric and nonparametric methods, the former represented by stochastic frontier analysis (SFA) and the latter by data envelopment analysis (DEA) (Wang et al., 2017). The substantive difference between these methods lies in their determination of the frontier. SFA estimates the parameters of the frontier of the production function by means of econometric modelling and then determines the technical efficiency. DEA seeks the production frontier by solving linear programming to find decision-making units (DMUs) on the frontier, whose technical efficiency value is 1 , for comparison with other DMUs to obtain the relative efficiency. Compared with SFA, DEA can be used to evaluate multi-input and multi-output 
systems without presupposing the production function form. In addition, its unit invariance property prevents the results measured by DEA from being affected by the data units.

Many scholars have studied TFEE issues using the DEA method. At the national level, Hu and Kao (2017) measured the TFEE of 17 Asia Pacific Economic Cooperation (APEC) countries and regions and found that Hong Kong, the Philippines and the United States are the most energy efficient. Zhang et al. (2011) compared the TFEE of 23 developing countries from 1980 to 2005. The results show that Botswana, Mexico and Panama have the highest efficiency, while Kenya, Sri Lanka and the Philippines have the lowest efficiency. Among the five countries with a sustained increase in TFEE, China's TFEE improvement was the most obvious. In China, Wang et al. (2017) estimated the TFEE of 35 subindustrial sectors in Beijing using the bootstrap-DEA model. Similar studies at the provincial level in China have employed the DEA method to estimate TFEE and energy-saving potential using data from the iron and steel industry (Feng et al., 2018) and to decompose the energy productivity in 35 industrial sectors into three factors (Wang, 2018). At the enterprise level, Song and Zheng (2016) used the DEA-based Malmquist productivity index to evaluate the variation in the environmental efficiency of thermoelectric enterprises. In Sweden, the efficiency of 14 industrial sectors was studied using industrial enterprise panel data (Zhang et al., 2016).

\subsection{TFEE and its decisive factors}

After calculation of the energy efficiency at various scales, the next question is what economic and social factors will exert an influence on it. According to previous studies, the social-economic factors mainly include technological progress, industrial structure, economic development level, energy consumption, energy price, degree of opening up, and government environmental control, etc (Song et al., 2013).

Specifically, although technological progress can save energy consumption and promote energy efficiency by affecting processes such as resource mining, transportation and end-use (Feng and Wang, 2017), this progress will also enlarge the economics of scale and generate new demand for energy, which will partially or even completely offset the saved energy through the rebound effect (Wei and Liu, 2017). Industrial structure is one of the important factors. From the perspective of the structural-bonus hypothesis, factors of production will shift from low-efficiency to 
high-efficiency sectors (Dension, 1967). Such a transfer will inevitably improve the overall economic efficiency. When the overall productivity growth rate exceeds the productivity growth rate of each sector, a "structural dividend" is generated. That economic restructuring can achieve energy efficiency improvements has been confirmed in many countries and regions (Kambara,1921; Lin and Karen, 1995). However, whether structural changes will definitely bring "dividends" to efficiency improvements remains controversial (Ang and Zhang, 2000).

The Tobit regression model is widely used to analyze the influencing factors of environmental efficiency. Zhang et al. (2016) confirmed that there is a significant positive correlation between GDP per capita, industrial structure, innovation capacity, environmental regulation, population density and environmental efficiency. Similar studies have also adopted the Tobit model (Xiong et al., 2019). Eco-efficiency is another index for evaluating sustainable urban development. Taking the eco-efficiency of 21 cities in Guangdong Province as the subject of investigation, Zhou et al. (2018) found that technological innovation, government intervention, openness and population density play a positive role in driving efficiency, while land use intensity, industrial structure and GDP per capita have a negative driving effect. Similar research was conducted by Wang and Wei (2014). To explore interdepartmental environmental efficiency, Zhou et al. (2013) studied the correlation between innovation capacity, power generation capacity, waste discharge fees, investment in pollutant treatment and environmental efficiency in the power industry. Similar studies on environmental efficiency include Fujii and Managi (2013).

In summary, the existing literature offers a rich discussion on TFEE and its influencing factors, providing a theoretical basis for follow-up studies; however, most of the studies focus on industrial sectors, interprovincial comparison or urban agglomeration. Few scholars have examined the sustainability problems of resourcebased cities. Li and Dewan (2017) evaluated the efficiency determinants of 116 resource-based cities, but their data period began in only 2012. To some extent, our study is a follow-up study of theirs, but we selected the data from 2010 to 2016, and the quantile panel regression was used to comprehensively analyze the impact of six economic and social variables on TFEE at each quantile level. As a unique type of city, resource-based cities follow a different life cycle from that of other cities.

Promoting the transformation of resource-based cities to achieve sustainable development is a major strategic issue for China, but also a worldwide problem. 
Through literature review, it is found that few quantitative studies on resource-based cities. The motivational contribution of this study is to explore the relationship between urban socioeconomic policy and resource constraints by examining the heterogeneity impacts of six determinants on resource-based cities, thus providing scientific guidance for future urban transformation.

\section{Data sources and methodology}

\subsection{Data sources}

Given the data available for comparison, 105 prefecture-level cities were selected from the National Plan for the Sustainable Development of Resource-based Cities (2013-2020). The plan divides resource-based cities into four types according to their resource supply and sustainability potential: growth-type, maturity-type, recession-type and regeneration-type. The resource reserves of growth-type cities are huge, which leads to the double growth of urban economic scale. The resource extraction in maturity-type cities reached its peak and has been stable for years. The level of urban construction is relatively high. The resources in recession-type cities have been exhausted, and quite a number of mines have been closed. Regeneration-type cities have basically got rid of resource dependence, and the economic driving force has been transformed into non-resource industries. Among the cities investigated in this study, 13 are growth-type, 57 are mature-type, 23 are recession-type and 12 are regenerationtype cities. Furthermore, 20, 36, 33 and 16 of the cities are located in the eastern, central, western and northeast regions, respectively. We use panel data to calculate the TFEE of these 105 cities in China from 2010 to 2016. The initial data are from the China City Statistical Yearbook and the statistical bulletins of national economic and social development in various cities.

\subsection{Nonparametric approach}

Based on previous academic studies, various environmental performance indicators are usually needed to measure TFEE. DEA is quite suitable for estimating this relative efficiency, considering multiple inputs and outputs. The DEA model was first proposed by Charnes et al. (1978) as a nonparametric efficiency evaluation approach, and its superiority lies in its lack of specific functional form or presupposed 
index weight and its dimensionless treatment of indicators, which promotes objectivity and reduces bias. The slack-based measure of efficiency in DEA proposed by Tone (2001) puts the slack variables directly into the objective function with the economic aim of maximizing the actual profit rather than simply maximizing the efficiency ratio. In most efficiency evaluations, multiple DMUs will be $100 \%$ effective; thus, accurate discrimination between these DMUs is practical for efficiency ranking and factor analysis. This study combines the super-efficiency model proposed by Tone (2002) and the SBM model to evaluate the TFEE of resource-based cities. The production possibility set (PPS) is defined as:

$$
\mathrm{P} \backslash\left(x_{0}, y_{0}\right)=\left\{(\bar{x}, \bar{y}) \mid \bar{x} \geq \sum_{k=1, \neq 0}^{K} \lambda_{k} x_{k}, \bar{y} \leq \sum_{k=1, \neq 0}^{K} \lambda_{k} y_{k}, \bar{y} \geq 0, \lambda \geq 0\right\}
$$

The subset was defined as:

$$
\bar{P} \backslash\left(x_{0}, y_{0}\right)=\mathrm{P} \backslash\left(x_{0}, y_{0}\right) \cap\left\{\bar{x} \geq x_{0} \text { and } \bar{y} \geq y_{0}\right\}
$$

When input or output is greater than 0 , the subset is not empty. Next, we consider a PPS with $\mathrm{n}$ DMUs, and each DMU has $m$ inputs, $r_{1}$ desirable outputs and $r_{2}$ undesirable outputs: $\mathrm{x} \in R^{m}, y^{d} \in R^{r_{1}}, y^{u} \in R^{r_{2}}$, and the matrices are defined as $X=$ $\left[x_{1} x_{2} \cdots x_{n}\right] \in R^{m \times n}, Y^{d}=\left[y_{1}^{d} y_{2}^{d} \cdots y_{n}^{d}\right] \in R^{r_{1} \times n}, Y^{u}=\left[y_{1}^{u} y_{2}^{u} \cdots y_{n}^{u}\right] \in R^{r_{2} \times n}$. Then, the super-SBM model is as follows:

$$
\begin{gathered}
p^{*}=\min \frac{\frac{1}{m} \sum_{i=1}^{m}\left(\frac{\bar{x}}{x_{i k}}\right)}{\left(\frac{\sum_{s=1}^{r_{1}} \overline{y^{d}}}{y_{s k}^{d}}+\frac{\sum_{q=1}^{r_{1}} \overline{y^{u}}}{y_{q k}^{u}}\right)} \\
\text { s.t. } \bar{x} \geq \sum_{j=1, \neq k}^{n} x_{i j} \lambda_{j}, \quad i=1,2, \cdots m, \\
\overline{y^{d}} \leq \sum_{j=1, \neq k}^{n} y_{s j}^{d} \lambda_{j}, \quad s=1,2, \cdots r_{1}, \\
\overline{y^{u}} \leq \sum_{j=1, \neq k}^{n} y_{q j}^{u} \lambda_{j}, \quad q=1,2, \cdots r_{2}, \\
\lambda_{j} \geq 0, \quad \mathrm{j}=1,2, \cdots, \mathrm{n} ; j \neq 0, \\
\bar{x} \geq x_{i}, k=1,2, \cdots, m, \\
\overline{y^{d}} \leq y_{k}^{d}, q=1,2, \cdots, r_{1}, \\
\overline{y^{u}} \leq y_{k}^{u}, u=1,2, \cdots, r_{2} .
\end{gathered}
$$


The target function value of $p^{*}$, that is, the TFEE value of every resources-based city, can be greater than 1 .

The selection of input-output indicators of DEA model should follow the principles of simplicity, relevance and diversity. In previous research regarding energy efficiency, capital, labor and energy were generally included in input indicators, while output indicators vary according to purposes. Based on the availability of urban panel data, this study selected annual electricity consumption, total investment in fixed assets, number of employees as energy input, capital input and labour input, respectively. Gross regional product was regarded as desirable output and three industrial emissions (industrial soot emissions, industrial sulfur dioxide emissions, industrial waste water discharge) were regarded as undesirable outputs.

\subsection{The spatiotemporal characteristics of TFEE}

The TFEE of the 105 prefecture-level resource-based cities from 2010 to 2016 is estimated by using the nonparametric approach with undesirable outputs described in section 3.2. To visually show the spatial and temporal evolution of TFEE, the ArcGIS software were adopted to produce distribution maps of the TFEE in each year. According to the TFEE values, the resource-based cities can be categorized into three levels: those with values greater than 1 , between 0.6 and 1 , and less than 0.6 . The higher the efficiency value is, the stronger the sustainability of the city's social and economic development. As shown in Figure 1, most resource-based cities are located in middleefficiency and low-efficiency areas, while fewer are located in high-efficiency areas. This shows that, on the whole, the TFEE of resource-based cities in China is at a low level, leaving much room for development. Furthermore, the distribution of the TFEE of resource-based cities shows the characteristics of local concentration and overall dispersion, without obvious regional agglomeration. Specifically, from 2010 to 2012, the number of cities in high-efficiency areas increased from 13 to 22, and from 2013 to 2016, the number was relatively stable. The efficiency values of Yangquan, Wuhai, Tongchuan, Baiyin and Shizuishan were all less than 0.6 during the period 2010-2016. These cities are located in the central provinces of Shanxi, Inner Mongolia, Shaanxi, Gansu and Ningxia. In contrast, the efficiency values of Lvliang, Erdos, Songyuan, Daqing, Dongying, Yan'an and Karamay were all higher than 1 during the period 20102016, and the GDP per capita in most of these cities is among the highest in the province. 
The TFEE of some cities, such as Heihe, Yunfu, Guangyuan and Yulin, showed a broad variation in efficiency during the period 2010-2016, which may be related to industrial agglomeration and policy adjustment. 

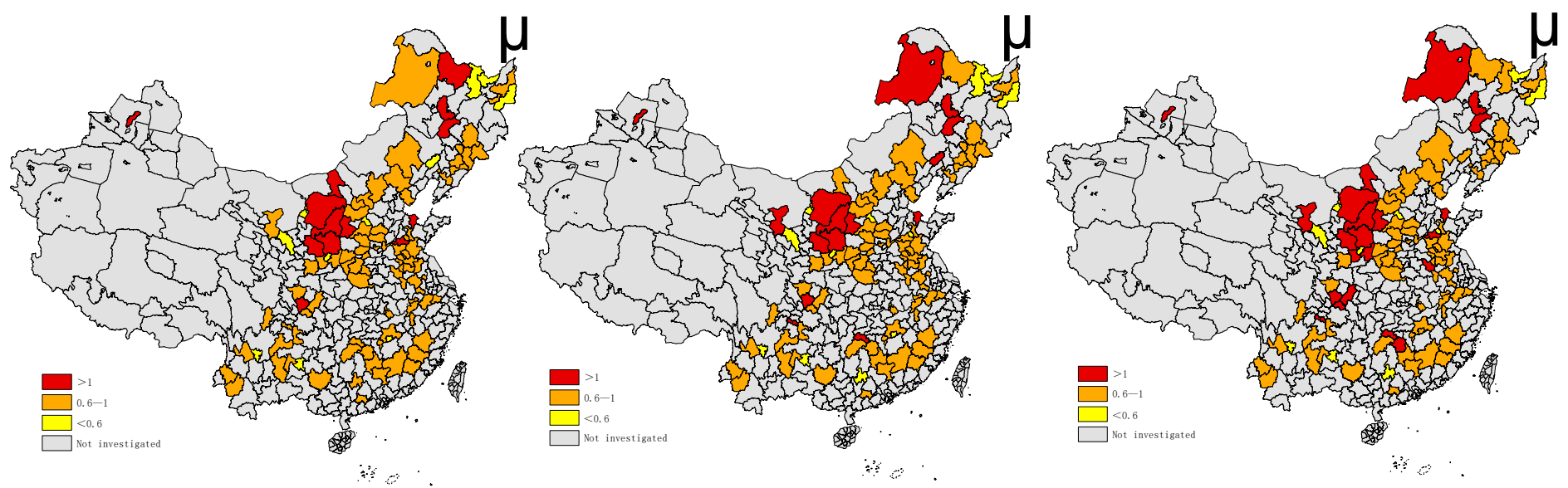

2010

2011

2012
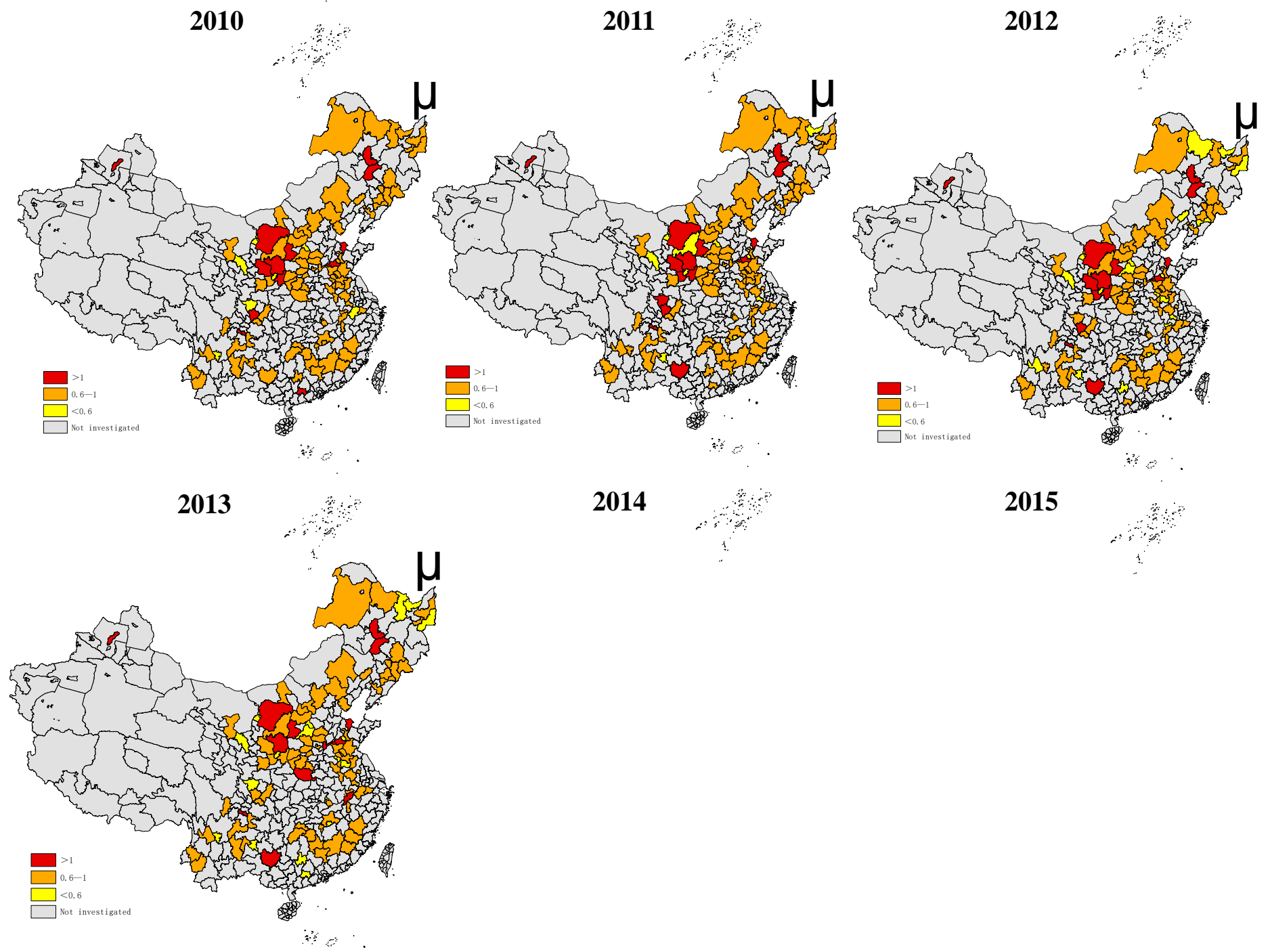

2014

2015

2016

Figure 1 TFEE in China's 105 resource-based cities (2010-2016)

\section{Empirical study}




\subsection{Economic and social variables}

The data we use consist of panel data of TFEE, GDP per capita (GPC), the proportion of secondary industry to GDP (IND), the proportion of mining industry population to working population (MP), the proportion of fiscal expenditure to GDP (FE), fuel and energy price index (PRI) and the amount of foreign capital utilized in fixed assets investment (FC) in 105 resource-based cities in China. The data are obtained from the National Bureau of Statistics of China and cover the period from 2010 to 2016. For the convenience of estimation and expression of large numbers, the GDP per capita is converted to the logarithmic form in this study.

Table 2 presents the descriptive statistics for all variables. As shown in Table 2, the skewness coefficients are not equal to 0 , which indicates that the variables are asymmetric. The positive kurtosis values indicate that the distributions of six variables have fatter tails, while the negative kurtosis value implies that the distribution of the fuel price index has thinner tails. In addition, the Jarque-Bera tests clearly show that all series depart from normality. These findings indicate that conditional mean regression may yield biased results and support the use of the panel quantile regression method in this research.

Table 2 Summary statistics

\begin{tabular}{cccccccc}
\hline Variables & TFEE & GPC & IND & MP & FE & PRI & FC \\
\hline Minimum & 0.3560 & 8.8809 & 14.9500 & 0.0237 & 4.1803 & 0.7699 & 0.0053 \\
Maximum & 1.2210 & 12.4564 & 89.7500 & 57.4088 & 68.7608 & 1.4352 & 8.7161 \\
Q1(.25) & 0.6640 & 10.0930 & 45.6400 & 2.5879 & 13.5734 & 1.0000 & 0.4881 \\
Q3(.75) & 0.8290 & 10.8492 & 59.2750 & 19.5434 & 23.3995 & 1.2156 & 2.8363 \\
Mean & 0.7621 & 10.4837 & 52.3347 & 12.1879 & 19.7147 & 1.1214 & 1.9349 \\
Stdev & 0.1619 & 0.5729 & 11.0684 & 12.2623 & 9.2135 & 0.1268 & 1.7305 \\
Skewness & 0.6301 & 0.4569 & -0.1981 & 1.2662 & 1.5371 & 0.0349 & 1.1415 \\
Kurtosis & 0.1940 & 0.4473 & 0.9646 & 1.0483 & 3.5348 & -0.8796 & 1.0253 \\
Jarque-Bera & 0.0000 & 0.0000 & 0.0000 & 0.0000 & 0.0000 & 0.0000 & 0.0000 \\
\hline
\end{tabular}

\subsection{Panel quantile regression}

The multivariate framework for investigating the impacts of GPC, IND, MP, FE, PRI and FC on TFEE across 105 resource-based cities in China is as follows:

$$
E E_{i, t}=f\left(G P C_{i, t}, I N D_{i, t}, M P_{i, t}, F E_{i, t}, P R I_{i, t}, F C_{i, t}\right)
$$

Using this model, we can examine the factors driving TFEE at different quantile levels. In the energy and environment areas, the data often have a distinct peak or fat 
tails. Compared with the ordinary least squares method, quantile regression does not require strong assumptions for error terms, in this situation, the quantile regression (Koenker and Bassett Jr, 1978) can provide more robust estimation results. Quantile regression can more comprehensively describe the conditional distribution of the explained variables, rather than simply analyze the conditional expectation of the explained variables. The estimators of regression coefficients are often different across quantiles, that is, the effects of explanatory variables on the explained variables are different across quantiles. To consider this and address unobserved individual heterogeneity, we build the following model:

$$
\begin{aligned}
& Q_{E E_{i, t}(\tau \mid \cdot)=} \alpha_{1, \tau} G P C_{i, t}+\alpha_{2, \tau} I N D_{i, t}+\alpha_{3, \tau} M P_{i, t}+\alpha_{4, \tau} F E_{i, t}+\alpha_{5, \tau} P R I_{i, t}+\alpha_{6, \tau} F C_{i, t} \\
& \quad+\beta_{i} \\
& i=1, \ldots, N, t=1, \ldots, T
\end{aligned}
$$

The main problem in the estimation of model (5) is unobserved individual heterogeneity. To address this issue, Koenker (2004) proposed a panel quantile regression model, which considers a penalty term in the minimization to eliminate unobserved fixed effects. Here, we will apply this method to estimate model (5), as follows:

$$
\begin{gathered}
\underset{\alpha}{\operatorname{argmin}} \sum_{k=1}^{K} \sum_{i=1}^{N} \sum_{t=1}^{T} w_{k} \rho_{\tau_{k}}\left\{E E_{i, t}-\alpha_{1, \tau} G P C_{i, t}-\alpha_{2, \tau} I N D_{i, t}-\alpha_{3, \tau} M P_{i, t}-\alpha_{4, \tau} F E_{i, t}\right. \\
\left.\quad-\alpha_{5, \tau} P R I_{i, t}-\alpha_{6, \tau} F C_{i, t}-\beta_{i}\right\}+\mu \sum_{i=1}^{N}\left|\beta_{i}\right| \\
i=1, \ldots, N, t=1, \ldots, T
\end{gathered}
$$

where $\rho_{\tau}(y)=\mathrm{y}\left(\tau-\mathbf{1}_{y<0}\right)$ is the traditional check function and $\mathbf{1}_{A}$ is the indicator function of set A. $K$ is the index for quantiles, and $w_{k}=1 / K$ is the weight of the $k$-th quantile, which controls the proportion of different quantile levels in this estimation (Chen and Lei, 2018; Cheng et al., 2018). $\mu$ is the tuning parameter to control the individual effects, which equals 1 in this paper (Zhu et al., 2016; Cheng et al., 2019).

\subsection{Panel unit root test}


Before we proceed to the rigorous empirical investigation with panel quantile regression models, we first investigate the order of integration of the variables considered in the study. Therefore, we apply the LLC test (Levin et al., 2002), IPS test (Im-Pesaran-Shin, 2003), Fisher-ADF test and Fisher-PP test (Choi 2001). The results of the panel unit root tests, shown in Table 3, indicate that the null hypothesis of the existence of a unit root can be strongly rejected for all the variables at the $1 \%$ significance level. Therefore, we will use the selected level in the following empirical analysis.

\section{Results and discussion}

\subsection{Empirical results}

In this section, we apply panel quantile regression to examine the impacts of the driving factors on the TFEE of 105 resource-based cities in China. To demonstrate the advantages of the quantile approach, we compare the OLS panel regression with panel quantile regression. In Table 4, column 2 shows the estimation results of the OLS panel regression, while other columns show the results of the panel quantile regression with fixed effects at different quantile levels. The estimation results indicate that the impacts of the six determinants on TFEE are heterogeneous. Figure 2 intuitively presents the estimation results and the patterns of the coefficients of the six driving factors across quantile levels.

First, panel quantile regression, the impact of GDP per capita (GPC) leads to a significant heterogeneous and asymmetric increase in TFEE (Figure 2a), while in the OLS regression, the impact is statistically nonsignificant and positive. Overall, from a statistical perspective, the impact of GPC is statistically significant and negative at lower quantiles and positive at higher quantiles, with the coefficient increasing from 0.072 at the 10th quantile to 0.099 at the 90th quantile. The negative coefficient indicates that an increase in GPC will reduce the TFEE at lower quantile levels, and the positive coefficient indicates that the GPC will increase the TFEE at higher quantile levels. These findings imply that the promotion of GPC may decrease TFEE in cities with lower efficiency values and increase TFEE in cities with higher efficiency values. The main reason is that cities with higher efficiency values will pay more attention to clean and sustainable development. 
Second, the findings show that the growth in the proportion of secondary industry to GDP (IND) plays an essential role in increasing TFEE across 105 resource-based cities in China (Figure 2b). There is a significant increasing trend in the impact of IND at different quantile levels, rising from 0 to 0.003 , which indicates that the impact is more prominent at higher levels of TFEE. Thus, the promotion of IND is helpful for efficiency growth, especially in cities that already have higher efficiency values. Moreover, the estimation results prove that OLS regression can present only part of information about the impact of IND on TFEE.

Third, the coefficient for the proportion of the mining industry population (MP) to the working population is statistically significant and negative at lower quantile levels but not significant at higher quantile levels (Figure 2c). In contrast, the coefficient of MP is nonsignificant in the OLS panel regression model, which indicates that OLS regression could not uncover the real impact of MP. The results indicate that when TFEE is relatively low, the MP may not significantly affect TFEE. Low-efficiency cities are more dependent than high-efficiency cities on natural resource extraction. Correspondingly, the growth of the mining industry will reduce TFEE.

Fourth, the impact of the proportion of fiscal expenditure (FE) on TFEE also follows an increasing trend (Figure 2d), which is statistically significant and negative at lower and medium quantile levels but not significant at higher quantiles and increases from -0.0064 to -0.0015 . This finding indicates that FE has a greater impact in cities with lower efficiency values than in cities with higher efficiency. This is mainly due to the greater stimulus of government action in low-efficiency regions and the lower levels of local government intervention in cities with higher efficiency.

Fifth, the impact of the fuel and energy price index (PRI) is statistically significant and symmetric around its median but nonsignificant at higher and lower quantiles (Figure 2e). The coefficient follows an inverted U-shaped curve trend, which first increases from 0.0541 to 0.2149 and then decreases to 0.0428 . These results indicate that the PRI has a significantly positive influence on TFEE. One possible explanation is that when fuel and energy prices are higher, local companies will try to reduce the energy demand and improve the efficiency of energy consumption.

Sixth, the foreign capital utilized in fixed assets investment (FC) has a significantly decreasing and negative impact on TFEE (Figure 2f). This finding provides support for the pollution haven hypothesis. The resource-based cities in China have cheap resources and relaxed environmental regulations, which attracts foreign investment to 
their high-energy consumption and heavy-polluting industries and thus decreases the TFEE in these cities.

Finally, we use Wald tests (Koenker and Bassett, 1982) to verify the heterogeneity of the coefficients by comparing the coefficients at the 10th quantile level with those at some higher quantiles $(0.3,0.5$ and 0.9 quantiles). Table 5 shows that the null hypothesis for all driving factors should be rejected, as the impacts of GPC, IND, MP, FE, PRI and FC on TFEE are heterogeneous across quantiles. These findings illustrate the advantages of considering the panel quantile approach to investigate the heterogeneous effects across the distribution of TFEE. In summary, compared with the OLS regression results, we can determine that the panel quantile model provides much more useful and complete information on the impacts of driven factors on TFEE in the 105 resource-based cities in China.

Table 5 Wald tests for the coefficient homogeneity ( 0.1 against $0.3,0.5$ and 0.9 quantiles)

\begin{tabular}{lllllll}
\hline & \multicolumn{2}{l}{ Against the 0.3 quantile } & \multicolumn{2}{l}{ Against the 0.5 quantile } & \multicolumn{2}{l}{ Against the 0.9 quantile } \\
\hline & $\begin{array}{l}\text { Test } \\
\text { statistic }\end{array}$ & P-Value & $\begin{array}{l}\text { Test } \\
\text { statistic }\end{array}$ & P-Value & $\begin{array}{l}\text { Test } \\
\text { statistic }\end{array}$ & P-Value \\
GPC & 1.653 & 0.199 & $4.903^{* *}$ & 0.027 & $21.824 * * *$ & 0.000 \\
IND & $3.513^{*}$ & 0.061 & $6.456^{* *}$ & 0.011 & $5.236^{* *}$ & 0.022 \\
MP & $10.413^{* * *}$ & 0.001 & $22.431^{* * *}$ & 0.000 & $4.657^{* *}$ & 0.031 \\
FE & $2.975^{*}$ & 0.085 & $11.636^{* * *}$ & 0.001 & $11.780^{* * *}$ & 0.001 \\
PRI & 1.358 & 0.244 & $9.306^{* * *}$ & 0.002 & 0.013 & 0.910 \\
FC & 1.583 & 0.208 & $3.824 *$ & 0.051 & $5.603 * *$ & 0.018 \\
\hline
\end{tabular}

Note: $*$ significant at $10 \%$ level; $* *$ significant at $5 \%$ level; $* * *$ significant at $1 \%$ level. 
Table 3 Panel unit root tests

\begin{tabular}{cccccccc}
\hline Variable & TFEE & GPC & IND & MP & FE & PRI & FC \\
\hline LLC & $-30.270^{* * * *}$ & $-42.432^{* * *}$ & $-22.058^{* * *}$ & $-340.000^{* * * *}$ & $-89.471^{* * *}$ & $-33.631^{* * *}$ & $-15.426^{* * *}$ \\
IPS & $-12.426^{* * * *}$ & $-44.761^{* * *}$ & $-4.628^{* * *}$ & $-46.009^{* * *}$ & $-17.380^{* * *}$ & $-3.121^{* * *}$ & $-9.992^{* * * *}$ \\
Fisher-ADF & $53.961^{* * *}$ & $57.664^{* * * *}$ & $34.908^{* * *}$ & $45.886^{* * *}$ & $49.780^{* * * *}$ & $15.513^{* * *}$ & $43.670^{* * * *}$ \\
Fisher-PP & $26.893^{* * *}$ & $53.986^{* * *}$ & $30.343^{* * *}$ & $15.830^{* * *}$ & $29.055^{* * *}$ & $222.912^{* * *}$ & $58.748^{* * *}$ \\
\hline
\end{tabular}

Table 4 Panel quantile regression results

\begin{tabular}{|c|c|c|c|c|c|c|c|c|c|c|}
\hline Variables & OLS & & & & & Quantiles & & & & \\
\hline \multirow{3}{*}{ (Intercept) } & & 0.1 & 0.2 & 0.3 & 0.4 & 0.5 & 0.6 & 0.7 & 0.8 & 0.9 \\
\hline & $0.4614^{* * * *}$ & $1.4088^{* * *}$ & $1.3070^{* * * *}$ & $1.0703^{\text {*** }}$ & $0.8713^{* * *}$ & $0.7810^{* * *}$ & $0.5476^{* *}$ & 0.0501 & -0.1387 & -0.2780 \\
\hline & $(0.1565)$ & $(0.1197)$ & $(0.2347)$ & $(0.2824)$ & $(0.2584)$ & $(0.2482)$ & $(0.2373)$ & $(0.1939)$ & $(0.1948)$ & $(0.4288)$ \\
\hline \multirow[t]{2}{*}{ GPC } & 0.0142 & $-0.0717^{* * * *}$ & $-0.0662^{* * * *}$ & $-0.0460^{* *}$ & -0.0311 & -0.0260 & -0.0102 & $0.0397^{* *}$ & $0.0664^{* * *}$ & $0.0988^{* * *}$ \\
\hline & $(0.0135)$ & $(0.0105)$ & $(0.0197)$ & $(0.0227)$ & $(0.0212)$ & $(0.0224)$ & $(0.0216)$ & $(0.0198)$ & $(0.0186)$ & $(0.0359)$ \\
\hline \multirow[t]{2}{*}{ IND } & $0.0017^{* *}$ & 0.0002 & 0.0006 & $0.0011^{* *}$ & $0.0015^{* * *}$ & $0.0019^{\text {*** }}$ & $0.0029^{* * *}$ & $0.0028^{* * *}$ & $0.0029^{* * *}$ & $0.0027^{* *}$ \\
\hline & $(0.0007)$ & $(0.0006)$ & $(0.0005)$ & $(0.0005)$ & $(0.0004)$ & $(0.0006)$ & $(0.0005)$ & $(0.0004)$ & $(0.0007)$ & $(0.0011)$ \\
\hline \multirow[t]{2}{*}{ MP } & 0.0000 & $-0.0028^{* * *}$ & $-0.0013^{* * *}$ & -0.0005 & -0.0002 & -0.0003 & 0.0001 & -0.0001 & 0.0003 & 0.0002 \\
\hline & $(0.0005)$ & $(0.0005)$ & $(0.0004)$ & (0.0004) & $(0.0003)$ & $(0.0003)$ & $(0.0003)$ & $(0.0005)$ & $(0.0011)$ & $(0.0014)$ \\
\hline \multirow[t]{2}{*}{$\mathrm{FE}$} & $-0.0023^{* * * *}$ & $-0.0064^{* * * *}$ & $-0.0047^{\text {**** }}$ & $-0.0044^{* * * *}$ & $-0.0033^{* * * *}$ & $-0.0030^{* * * *}$ & $-0.0023^{\text {**** }}$ & $-0.0015^{* *}$ & $-0.0021^{* *}$ & 0.0031 \\
\hline & $(0.0008)$ & $(0.0008)$ & $(0.0009)$ & $(0.0010)$ & $(0.0010)$ & $(0.0008)$ & $(0.0007)$ & $(0.0007)$ & $(0.0009)$ & $(0.0026)$ \\
\hline \multirow[t]{2}{*}{ PRI } & $0.1141^{* *}$ & 0.0541 & $0.0867^{*}$ & $0.1182^{* * *}$ & $0.1382^{* * * *}$ & $0.1754^{* * *}$ & $0.2115^{* * *}$ & $0.2149^{* * *}$ & $0.1947^{* * * *}$ & 0.0428 \\
\hline & $(0.0463)$ & $(0.0453)$ & $(0.0495)$ & $(0.0424)$ & $(0.0350)$ & (0.0397) & $(0.0496)$ & $(0.0356)$ & $(0.0474)$ & $(0.0887)$ \\
\hline \multirow[t]{2}{*}{ FC } & $-0.0093^{* * *}$ & 0.0008 & -0.0032 & $-0.0049^{* *}$ & $-0.0069^{* * * *}$ & $-0.0077^{* * * *}$ & $-0.0102^{* * *}$ & $-0.0123^{* * *}$ & $-0.0149^{* *}$ & $-0.0144^{*}$ \\
\hline & $(0.0035)$ & $(0.0038)$ & $(0.0035)$ & $(0.0024)$ & $(0.0023)$ & $(0.0028)$ & $(0.0036)$ & $(0.0037)$ & $(0.0059)$ & $(0.0077)$ \\
\hline
\end{tabular}

Note: Numbers in the parentheses represent standard deviation. * significant at $10 \%$ level; ** significant at $5 \%$ level; *** significant at $1 \%$ level. 


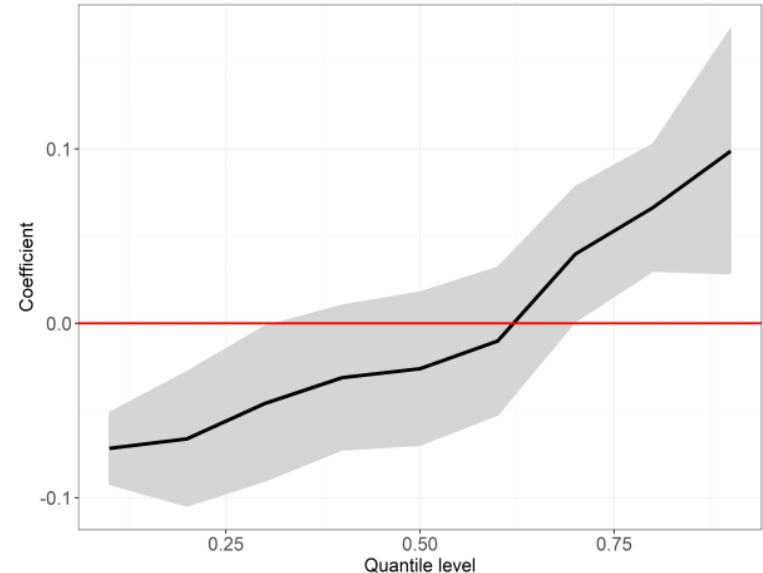

(a) GPC

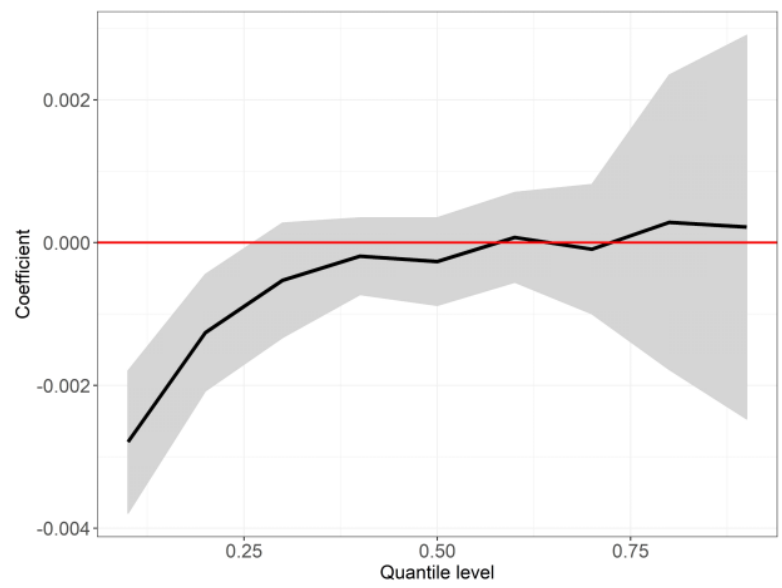

(c) MP

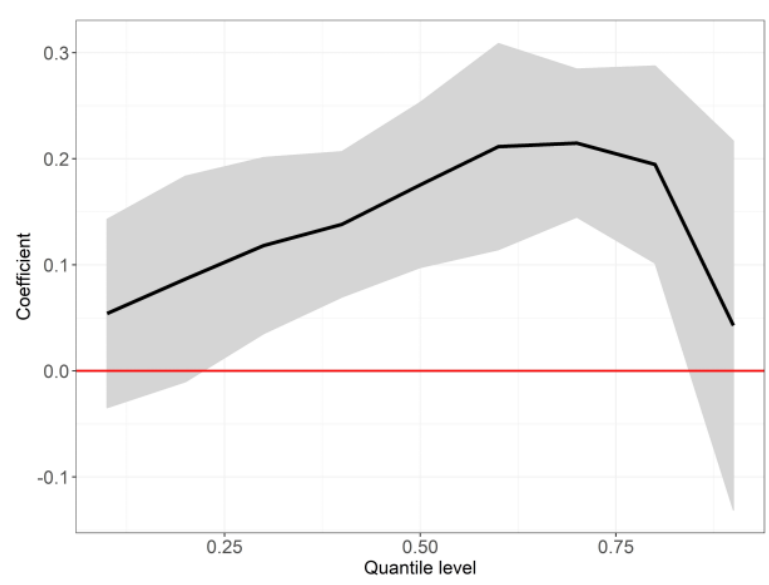

(e) PRI

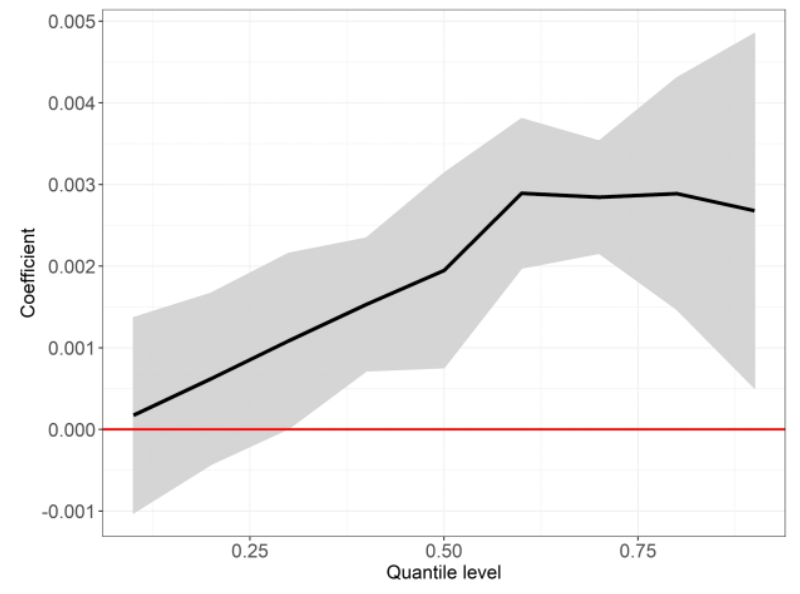

(b) IND

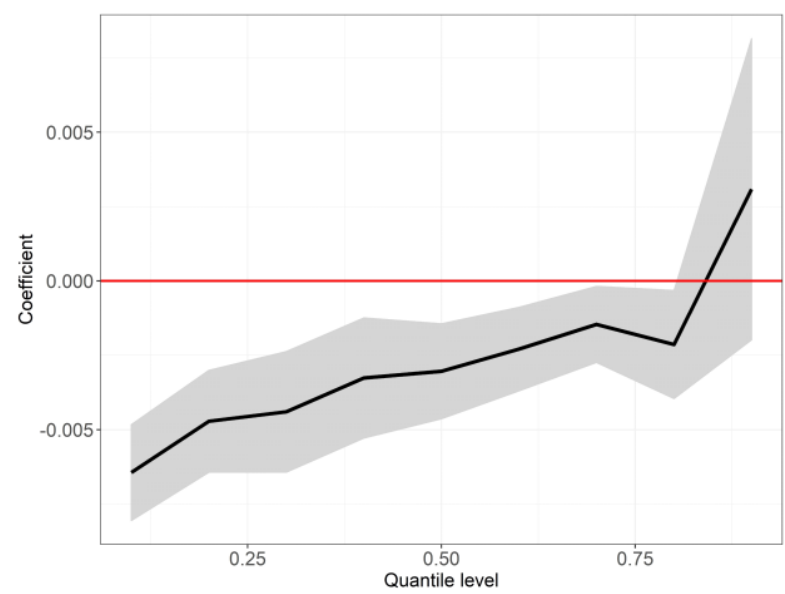

(d) FE

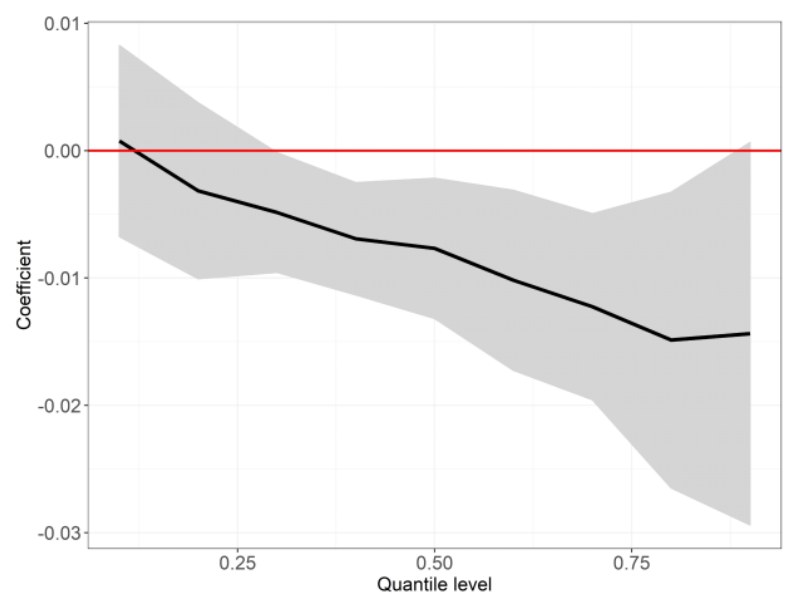

(f) $\mathrm{FC}$

Figure 2. Change in panel quantile regressions coefficients. Notes: The $x$-axis denotes the conditional quantiles of the energy efficiency, and the y-axis presents the coefficient values of different variables. Shaded areas correspond to $95 \%$ confidence intervals of quantile estimation. 


\subsection{Discussion}

The results reveal some interesting findings. First, IND exerts a positive and significant effect on TFEE, which is contrary to the results of other studies that have investigated TFEE. Different industries require different energy volume. The primary industry is labor-intensive and consumes less energy. The secondary industry consists of sectors such as mining and processing, which have a high capital concentration and use machinery in production and thus consume much energy. In the tertiary industry, the coexistence of machinery and human labor in production requires energy consumption only as an auxiliary condition for production or service activities. The structural-bonus hypothesis holds that essential productive factors will shift from inefficient sectors to efficient sectors, thus improving the overall economic efficiency (Denison, 1967). However, whether changes in regional industrial structure have a positive impact on energy efficiency has not been unanimously concluded. Some scholars find that these changes are not significant or can be tenable only under certain restrictive conditions by adopting different samples (Timmer and Szirmai, 2000; Ezcurra et al.,2007).

Second, the relationship between the energy price and TFEE shows an inverted Ushaped curve as efficiency increases. Theoretically, rising energy prices will encourage energy users to adopt alternative energy sources or improve energy utilization technologies, thereby promoting TFEE. Conversely, if the energy price is lower than the reasonable price, there will be inefficient use of energy (Hsieh and Klenow, 2009). According to their analysis of panel data for 39 countries, Wang et al. (2014) found that the positive effect of energy prices on energy efficiency is more significant in developing countries than in developed countries. Although the results obtained by this study show that energy price has a positive driving effect on efficiency, this effect varies according to the efficiency changes, and the magnitude of influence is unstable.

Third, a city's openness exerts a rather negative effect on TFEE. This partly supports the pollution haven hypothesis, according to which enterprises in pollutionintensive industries tend to choose countries or regions with relatively low environmental standards for production activities, which causes pollution transfer (Walter, 1979). Generally, a city's openness influences energy efficiency through technology spillover, international trade and the international division of labor. Through technology spillover, foreign capital can improve the technology level, 
organizational efficiency and management skills in host countries. Through international trade, a country can import a large number of products that consume less energy abroad as intermediate inputs, thus reducing the energy inputs. In the international division of labor, countries with abundant knowledge elements produce high-end products, countries with abundant human capital produce intermediate products, and countries with abundant labor elements produce primary products. China is at the bottom of the global value chain and engages in the processing of low valueadded energy products. Therefore, the more foreign investment a resource-based city receives, the lower its energy and technology efficiency.

\section{Conclusion and policy implications}

Based on a balanced panel data of the urban economy, this study estimates the TFEE of 105 resource-based cities in China by using a nonparametric method and analyses the spatiotemporal characteristics of the change in TFEE, which reflects the sustainability of urban development to a certain extent. This study identifies the multidimensional socioeconomic factors affecting TFEE, which can provide a better understanding of the relationship between energy utilization and economic and social development in resource-based cities.

The panel quantile regression was applied to analyze the multiple impacts of GPC, IND, MP, PRI, FE and FC on the TFEE of 105 resource-based cities. This approach can estimate the model parameters at different quantile levels, uncover the dynamic influence of various factors on TFEE and then provide theoretical support for improving TFEE. The main findings are shown in Figure 3.

Firstly, the impacts of six decisive factors on TFEE are heterogeneous across different quantiles. Specifically, IND and PRI exert positive effects on TFEE, and the coefficients increase across quantiles. FC and MP exert negative effects on TFEE, and the coefficients changes across quantiles. Among them, GPC shows stronger heterogeneity than other factors, and PRI exerts the most significant effect on TFEE. The influence of PRI on TFEE shows an inverted U-shaped distribution as the quantile increases, which in accordance with the law of diminishing marginal productivity. 


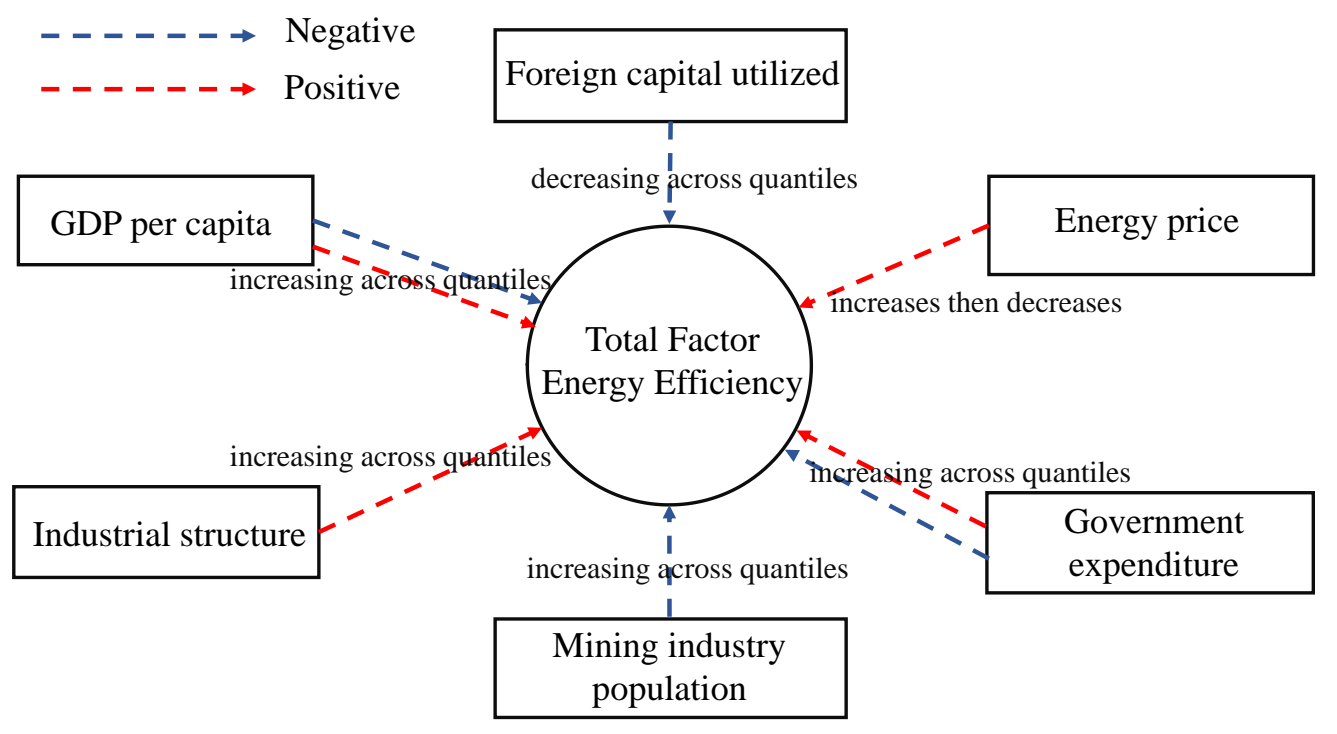

73

74

Figure 3. Relationships between GPC, IND, MP, FE, PRI, FC and TFEE.

Meanwhile, Resource-based cities with lower efficiency are more sensitive to government behavior than cities with higher efficiency. This may be because enterprises tend to ignore the feedback of government intervention and environmental regulation after resource-based cities enter the mature stage. City openness has a negative effect on TFEE, which partly supports the pollution haven hypothesis. The more foreign investment a resource-based city receives, the lower its energy and technology efficiency.

In reality, improving the resource utilization level and achieving sustainable urban development cannot be accomplished by the efforts of one actor. Instead, it requires joint action and cross-border cooperation among different enterprises, organizations and even countries. The low sustainability of most resource-based cities in China is worrying. The resources in some cities have been exhausted, and these cities face severe pressure for transformation. The government plays an extremely important role in urban transformation as not only the main provider of urban public services, residents' living security and environmental governance but also the guardian of fairness and efficiency. According to the empirical findings in this study, we provide the following suggestions to help resource-based cities improve their sustainability.

(1) Long-term energy price supervision is necessary. Against the background of rapid urbanization in China, low prices of energy products may lead to a surge in energy demand and energy waste. The influence of the energy price on TFEE is mainly realized 
through the supply-demand relationship. The empirical results of this study verify the positive impact of the energy price on TFEE at the middle and low levels but not at the high level. Therefore, when resource-based cities are in the recession or transition phase, that is, when TFEE is the lowest, policymakers can raise energy prices appropriately to stimulate energy conservation.

(2) Policymakers should create a positive environment for the development of resource-based cities and provide a good platform for attracting external investment, talents and advanced technology. Specifically, special funds for urban transformation could be established, as resource-based cities have abundant natural resources, land and labor, which creates convenient conditions for attracting foreign investment. In terms of talent, urban transformation is bound to result in the unemployment of some workers, so the founding of small enterprises with lower costs can be encouraged to not only enhance market vitality but also employ workers who become temporarily unemployed. In terms of technology, new metal catalysts can achieve better energy conversion capacity (Li and Henkelman, 2017; Li et al., 2018), thus bringing more economic benefits.

(3) The proportion of the mining population to a certain extent reflects the dependence of a city on the mining industry. The higher a resource-based city's dependence on the mining industry is, the less sustainable its development. This is because as the resource extraction cost progressively increases and the limited resources are gradually exhausted, cities will enter a recession phase. Therefore, the cities can implement renewable energy development plans to mitigate atmospheric pollutant emissions (Yu et al., 2018). But more importantly, by developing non-mineral industries to adjust and optimize the industrial structure could allow the city to escape the typical life cycle of resource-dependent areas.

\section{Acknowledgments}

The authors are grateful for financial support by Shenzhen Municipal Development and Reform Commission, Shenzhen Environmental Science and New Energy Technology Engineering Laboratory, Grant Number: SDRC [2016]172; the National Natural Science Foundation of China under Grant No.71803182; No.21808119 and China Postdoctoral Science Foundation under Grant No. 
128

\section{Reference}

Ang B W, Zhang F Q. A survey of index decomposition analysis in energy and environmental studies[J]. Energy, 2000, 25(12): 1149-1176.

Charnes A, Cooper W W, Rhodes E. Measuring the efficiency of decision making units[J]. European journal of operational research, 1978, 2(6): 429-444.

Chen W, Lei Y. The impacts of renewable energy and technological innovation on environment-energy-growth nexus: New evidence from a panel quantile regression[J]. Renewable Energy, 2018, 123: 1-14.

Cheng C, Ren X, Wang Z, et al. Heterogeneous impacts of renewable energy and environmental patents on CO2 emission-Evidence from the BRIICS[J]. The Science of the total environment, 2019.

Cheng C, Ren X, Wang Z, et al. The Impacts of Non-Fossil Energy, Economic Growth, Energy Consumption, and Oil Price on Carbon Intensity: Evidence from a Panel Quantile Regression Analysis of EU 28[J]. Sustainability, 2018, 10(11): 4067.

Choi I. Unit root tests for panel data[J]. Journal of international money and Finance, 2001, 20(2): 249-272.

Denison E F, Poullier J P. Why growth rates differ: postwar experience in nine western countries[M]. Washington, DC: Brookings Institution, 1967.

Elliott R J R, Sun P, Zhu T. The direct and indirect effect of urbanization on energy intensity: A province-level study for China[J]. Energy, 2017, 123: 677-692.

Ezcurra R, Pascual P, Rapún M. Spatial inequality in productivity in the European union: sectoral and regional factors[J]. International Regional Science Review, 2007, 30(4): 384-407.

Feng C, Huang J B, Wang M, et al. Energy efficiency in China's iron and steel industry: Evidence and policy implications[J]. Journal of Cleaner Production, 2018, 177: 837-845.

Feng C, Wang M. Analysis of energy efficiency and energy savings potential in China's provincial industrial sectors[J]. Journal of cleaner production, 2017, 164: 15311541.

Fujii H, Managi S. Determinants of eco-efficiency in the Chinese industrial sector[J]. Journal of Environmental Sciences, 2013, 25: S20-S26.

Harris C D. A functional classification of cities in the United States[J]. Geographical Review, 1943, 33(1): 86-99.

Hsieh C T, Klenow P J. Misallocation and manufacturing TFP in China and India[J]. The Quarterly journal of economics, 2009, 124(4): 1403-1448.

$\mathrm{Hu} \mathrm{J}$ L, Kao C H. Efficient energy-saving targets for APEC economies[J]. Energy policy, 2007, 35(1): 373-382.

$\mathrm{Hu} \mathrm{J}$ L, Wang S C. Total-factor energy efficiency of regions in China[J]. Energy policy, 2006, 34(17): 3206-3217.

Im K S, Pesaran M H, Shin Y. Testing for unit roots in heterogeneous panels[J]. Journal of econometrics, 2003, 115(1): 53-74.

Jianhui Y U , Jiaming L I , Wenzhong Z . Identification and classification of resource-based cities in China[J]. Acta Geographica Sinica, 2018.

Koenker R, Bassett G. Tests of linear hypotheses and 1" 1 estimation[J]. Econometrica: Journal of the Econometric Society, 1982: 1577-1583. 
Koenker R, Bassett Jr G. Regression quantiles[J]. Econometrica: journal of the Econometric Society, 1978: 33-50.

Koenker R. Quantile regression for longitudinal data[J]. Journal of Multivariate Analysis, 2004, 91(1): 74-89.

Levin A, Lin C F, Chu C S J. Unit root tests in panel data: asymptotic and finitesample properties[J]. Journal of econometrics, 2002, 108(1): 1-24.

Li B, Dewan H. Efficiency differences among China's resource-based cities and their determinants[J]. Resources Policy, 2017, 51: 31-38.

Li H, Evans Jr E J, Mullins C B, et al. Ethanol Decomposition on Pd-Au Alloy Catalysts[J]. The Journal of Physical Chemistry C, 2018, 122(38): 22024-22032.

Li H, Henkelman G. Dehydrogenation selectivity of ethanol on close-packed transition metal surfaces: a computational study of monometallic, $\mathrm{Pd} / \mathrm{Au}$, and $\mathrm{Rh} / \mathrm{Au}$ catalysts[J]. The Journal of Physical Chemistry C, 2017, 121(49): 27504-27510.

Li H, Long R, Chen H. Economic transition policies in Chinese resource-based cities: an overview of government efforts[J]. Energy Policy, 2013, 55: 251-260.

Lin X, Polenske K R. Input-output anatomy of China's energy use changes in the 1980s[J]. Economic Systems Research, 1995, 7(1): 67-84.

Ma B. Does urbanization affect energy intensities across provinces in China? Long-run elasticities estimation using dynamic panels with heterogeneous slopes[J]. Energy Economics, 2015, 49: 390-401.

Nelson H J. A service classification of American cities[J]. Economic geography, 1955, 31(3): 189-210.

Rafiq S, Salim R, Nielsen I. Urbanization, openness, emissions, and energy intensity: a study of increasingly urbanized emerging economies[J]. Energy Economics, 2016, 56: 20-28.

Song M, Song Y, An Q, et al. Review of environmental efficiency and its influencing factors in China: 1998-2009[J]. Renewable and Sustainable Energy Reviews, 2013, 20:8-14.

Song M, Zheng W. Computational analysis of thermoelectric enterprises' environmental efficiency and Bayesian estimation of influence factors[J]. The Social Science Journal, 2016, 53(1): 88-99.

Tatsu K. The Energy Situation in China[J]. China Quarterly, 1992, 131(131):608636.

Timmer M P, Szirmai A. Productivity growth in Asian manufacturing: the structural bonus hypothesis examined[J]. Structural change and economic dynamics, 2000, 11(4): 371-392.

Tone K. A slacks-based measure of efficiency in data envelopment analysis[J]. European journal of operational research, 2001, 130(3): 498-509.

Tone K. A slacks-based measure of super-efficiency in data envelopment analysis[J]. European Journal of Operational Research, 2002, 143(1):32-41.

Walter I, Ugelow J L. Environmental policies in developing countries[J]. Ambio, 1979: 102-109.

Wang J M, Shi Y F, Zhang J. Energy efficiency and influencing factors analysis on Beijing industrial sectors[J]. Journal of Cleaner Production, 2017, 167: 653-664.

Wang K, Wei Y M. China's regional industrial energy efficiency and carbon emissions abatement costs[J]. Applied Energy, 2014, 130: 617-631.

Wang R. Energy efficiency in China's industry sectors: A non-parametric production frontier approach analysis[J]. Journal of Cleaner Production, 2018, 200: 880-889. 
Wei T, Liu Y . Estimation of global rebound effect caused by energy efficiency improvement[J]. Energy Economics, 2017:S0140988317301949.

Xiong S, Ma X, Ji J. The impact of industrial structure efficiency on provincial industrial energy efficiency in China[J]. Journal of Cleaner Production, 2019.

Yu L, Li Y P, Huang G H, et al. A copula-based flexible-stochastic programming method for planning regional energy system under multiple uncertainties: a case study of the urban agglomeration of Beijing and Tianjin[J]. Applied energy, 2018, 210: 6074.

Zhang J , Zeng W , Shi H . Regional environmental efficiency in China: Analysis based on a regional slack-based measure with environmental undesirable outputs[J]. Ecological Indicators, 2016, 71:218-228.

Zhang S, Lundgren T, Zhou W. Energy efficiency in Swedish industry: A firmlevel data envelopment analysis[J]. Energy Economics, 2016, 55: 42-51.

Zhang X P, Cheng X M, Yuan J H, et al. Total-factor energy efficiency in developing countries[J]. Energy Policy, 2011, 39(2): 644-650.

Zhou C, Shi C, Wang S, et al. Estimation of eco-efficiency and its influencing factors in Guangdong province based on Super-SBM and panel regression models[J]. Ecological Indicators, 2018, 86: 67-80.

Zhou Y, Xing X, Fang K, et al. Environmental efficiency analysis of power industry in China based on an entropy SBM model[J]. Energy Policy, 2013, 57: 68-75.

Zhu H, Duan L, Guo Y, et al. The effects of FDI, economic growth and energy consumption on carbon emissions in ASEAN-5: evidence from panel quantile regression[J]. Economic Modelling, 2016, 58: 237-248. 